\title{
Dez espécies de bambus exóticos mais comuns no paisagismo no Brasil $^{(1)}$
}

\author{
ANTONIO FERNANDO CAETANO TOMBOLATO(2); \\ THIAGO MACHADO GRECO(3); MOISÉS MEDEIROS PINTO(4)
}

\begin{abstract}
RESUMO
Embora no Brasil existam mais de 230 espécies nativas, os bambus mais comumente encontrados em cultivo são exóticos, provavelmente introduzidos no País pelos colonizadores portugueses e imigrantes japoneses. A semelhança entre o aspecto vegetativo das espécies tem levado a erros de nomenclatura e, portanto, um dos objetivos deste trabalho é fornecer subsídios suficientes para a correta identificação das dez espécies cultivadas mais comuns.

Palavras-chave: Bambusoideae, nomenclatura, identificação.
\end{abstract}

\section{ABSTRACT}

Ten species of more common exotic bamboos in the landscape in Brazil

While in Brazil there are more than 230 native species, bamboos most commonly found in cultivation are exotic, probably introduced into the country by the Portuguese and Japanese immigrants. The similarity between the vegetative aspect of the species has led to naming errors, and therefore one of the goals of this work is to provide enough subsidies for the correct identification of the ten most common cultivated species in this country.

Keywords: Bambusoideae, nomenclature, identification.

\begin{abstract}
A história
O termo genérico bambu se refere à subfamília Bambusoideae, da família Poaceae. Embora no Brasil existam aproximadamente 230 espécies nativas (FILGUEIRAS e SANTOS-GONÇALVES, 2004), os bambus mais comumente, para não afirmar sua totalidade, encontrados cultivados nos jardins e beiras de estradas no Brasil são exóticos.

A origem da introdução desses materiais no País perdese no tempo da história da colonização.

O IAC, durante as décadas de 1950 e 1960, introduziu, através da sua Seção de Botânica Econômica (existente na época), hoje transformada no Jardim Botânico IAC, dezenas de espécies de bambu majoritariamente do tipo entouceirante e de interesse agroindustrial (Figura 1). $\mathrm{O}$ levantamento dos dados referentes àquelas espécies introduzidas vem sendo feito, porém, aparentemente, não existe ligação direta com as espécies mais comuns encontradas em uso no paisagismo do Brasil, de modo geral.

A migração japonesa também exerceu forte influência na introdução principalmente das espécies do tipo alastrante, como é o caso do bambu "mossô" (Phyllostachys edulis (Carrière) J. Houz), cultivado para a produção de brotos comestíveis.
\end{abstract}

Ainexistência de registros em língua portuguesa e mesmo a falta de controle governamental sobre a introdução legal, há provavelmente cem anos, dessas espécies alastrantes no País leva simplesmente a suposições. Contudo, observase a ocorrência de tais espécies precisamente nas regiões onde as colônias nipônicas se estabeleceram, o que torna as evidências mais contundentes.

Pode-se levar à mesma inferência para o caso da introdução das espécies entouceirantes supostamente feita pelos colonizadores portugueses. Observam-se plantios muito antigos de bambu nas regiões litorâneas próximas às cidades históricas e antigas fazendas.

\section{Os bambus exóticos mais comuns}

Existem diversas formas de crescimento das espécies de bambus, que estão intimamente ligadas à estrutura dos rizomas. De um modo geral, as espécies são classificadas como entouceirantes, de rizoma do tipo paquimorfo, mais comumente encontradas nas regiões tropicais, ou alastrantes, de rizoma do tipo leptomorfo, que ocorrem predominantemente em regiões de clima temperado.

A forma de crescimento dos rizomas deve influir no uso das espécies de bambu no paisagismo. Os tipos entouceirantes, pela sua arquitetura, podem substituir árvores e arbustos em um projeto paisagístico, observando-

\footnotetext{
(1) Recebido em 11/03/2012 e aceito para publicação em 14/11/2012.

(2) Pesquisador Científico, Instituto Agronômico - IAC, NPD Jardim Botânico, Av. Barão de Itapura, 1481, CEP:13012-970 - Campinas, SP. E-mail: tombolat@iac.sp.gov.br. Bolsista DT CNPq.

(3) Engenheiro Florestal. Mestrando. Pós-Graduação em Biologia Vegetal. Universidade Federal de Santa Catarina, Campus Universitário, Departamento de Botânica, Trindade, CEP: 88040-900 - Florianópolis, SC - Brasil.

(4) Projetista, Pesquisador autônomo em bambu.
} 


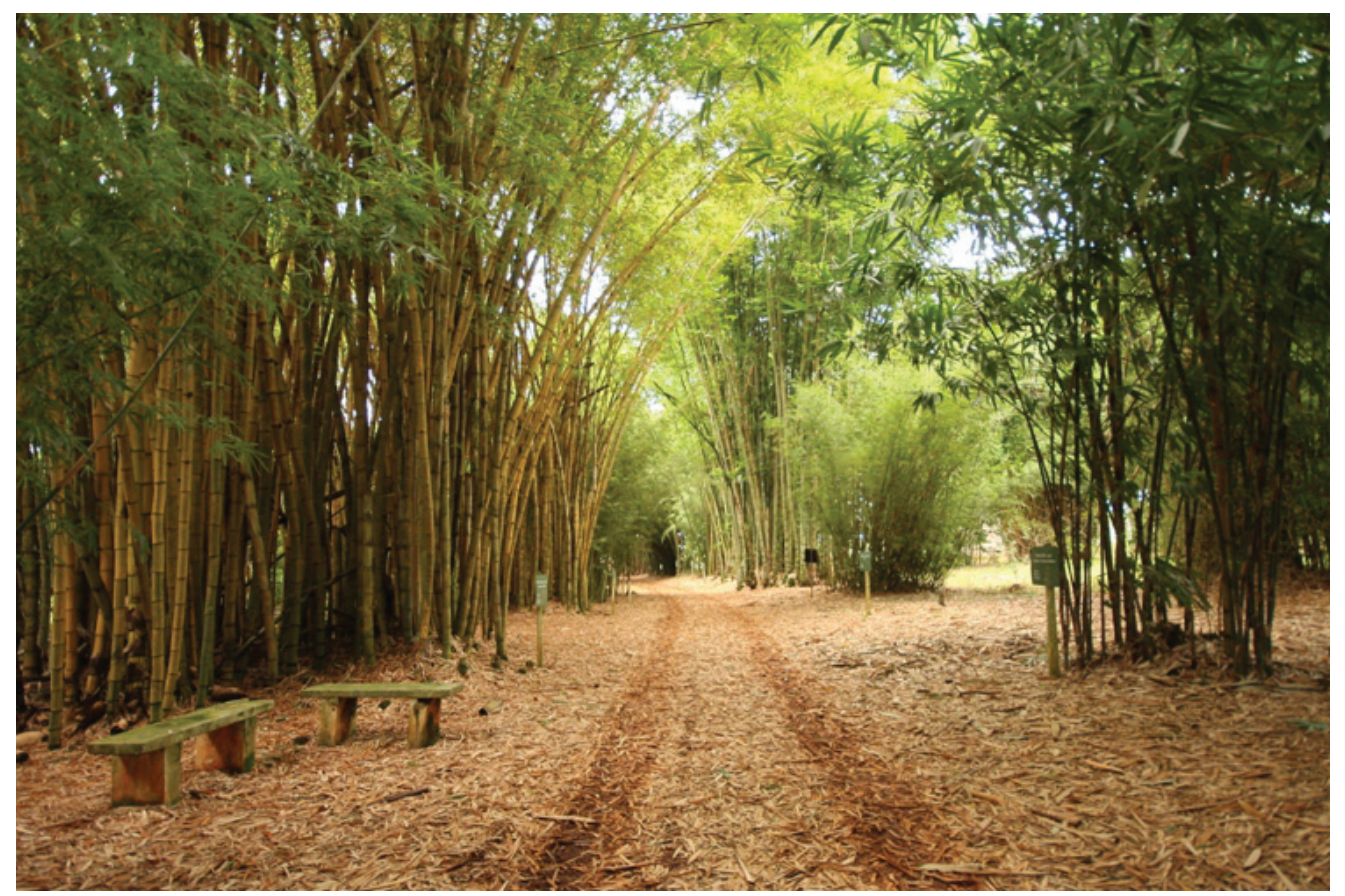

Figura 1. Vista parcial da coleção de bambus da UPD de Tatuí. Foto: Felipe Faustini Palma.

Figure 1. Partial view of bamboo collection at UPD-Tatuí.

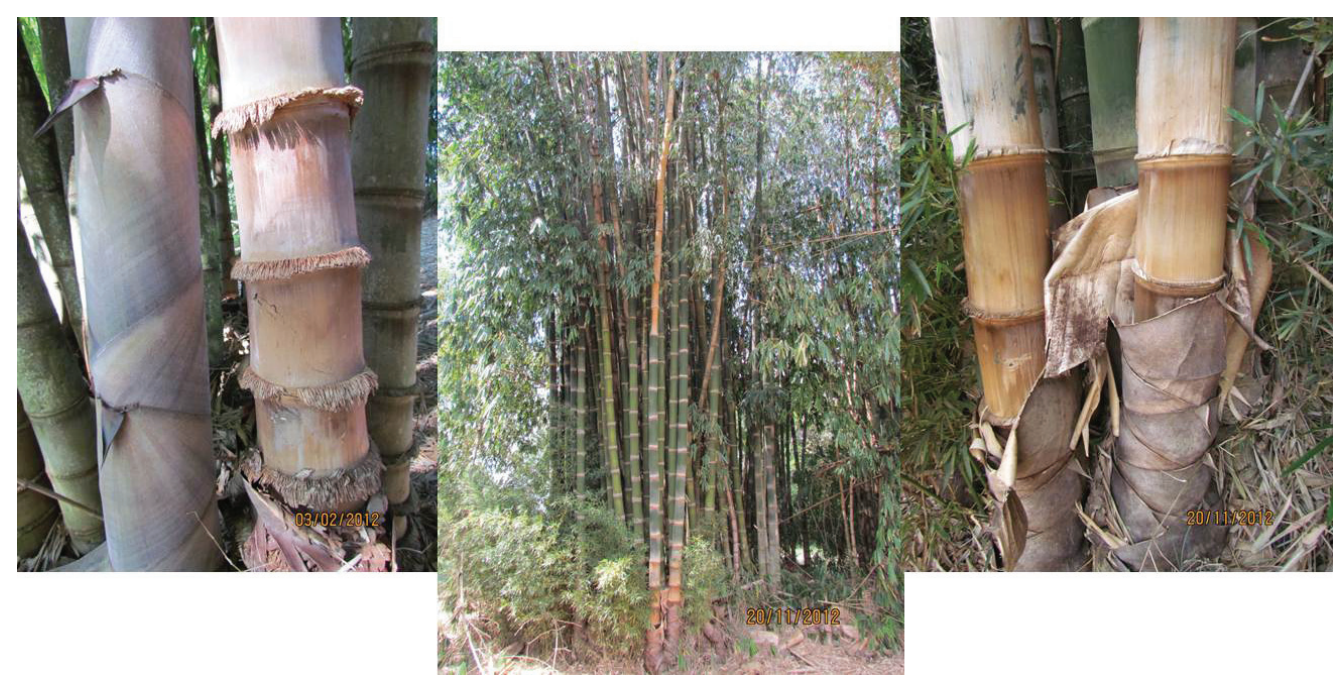

Figura 2. Dendrocalamus asper (Schult. \& Schult.f.) Baker ex K.Heyne.

se que os colmos velhos (com mais de 5-6 anos) devem ser retirados para manter a beleza das touceiras. Os alastrantes podem ajudar na contenção de erosões e também para formar uma barreira visual. A poda e a eliminação de colmos mais velhos também ajudam a mantê-los com melhor aspecto visual.

A escolha das dez espécies mais comuns listadas neste documento foi baseada no consenso entre seus autores e confirmada pelo trabalho de FILGUEIRAS e SANTOSGONÇALVES (2004) (Tabela 1).

A utilização e a atualização dos nomes científicos citados no presente artigo foram extraídas preferencialmente de FILGUEIRAS (2011); entretanto, as respectivas sinonímias botânicas e os dados faltantes naquela publicação foram buscados em outras fontes como em OHRNBERGER (2002) e na página eletrônica do Missouri Botanical Garden - www. tropicos.org.

\section{Espécies Entouceirantes}

1- Dendrocalamus asper (Schult. \& Schult.f.) Baker ex K.Heyne

Sinonímia: Gigantochloa aspera (Schult. \& Schult. f.) Kurz, Dendrocalamus flagellifer Munro

Nome popular: bambu gigante, bambu balde.

Origem: Sudeste da Ásia. Foi provavelmente trazido para o país pelos colonizadores portugueses.

Características: Apresenta touceiras de grande porte, com até $30 \mathrm{~m}$ de altura, e diâmetro dos colmos na base podem atingir mais de $30 \mathrm{~cm}$ em touceiras cultivadas no Brasil. Os colmos jovens são cobertos por tricomas que lhes conferem uma coloração marrom. Desenvolve-se melhor a pleno sol e tolera temperaturas de até $-5^{\circ} \mathrm{C}$. É o bambu de maior porte encontrado no Brasil, comumente identificado 
Tabela 1. Lista das espécies mais comuns de bambus cultivadas no Brasil (FILGUEIRAS e SANTOS-GONÇALVES, 2004)

Table 1. List of more commom bamboo species cultivated in Brazil

\begin{tabular}{|c|c|c|}
\hline Nomenclatura Botânica Científica & Nomenclatura Popular & Obs. \\
\hline Bambusa blumeana Schult. \& Schult. f. & - & Raro \\
\hline B. dissimulator McClure & - & Raro \\
\hline B. multiplex (Lour.) Raeusch. ex Schult. \& Schult. f. & $\begin{array}{l}\text { Bambu-multiplex, bambu- } \\
\text { folha-de samambaia }\end{array}$ & Comum \\
\hline B. tulda Roxb. & - & Raro \\
\hline B. tuldoides Munro & - & Raro \\
\hline B. ventricosa McClure & Bambu barrigudo & Raro \\
\hline B. vulgaris Schrad. ex J.C. Wendl. & Bambu, bambu comum & Difuso \\
\hline Dendrocalamopsis beecheyana (Munro) Keng f. & - & Raro \\
\hline Dendrocalamus asper (Schult. \& Schult. f.) Backer ex K. Heyne & Bambu balde, bambu gigante & Comum \\
\hline D. latiflorus Munro & - & Raro \\
\hline D. strictus & Bambu balde, bambu gigante & Raro \\
\hline Gigantochloa apus (Schult. \& Schult. f.) Kurz & - & Raro \\
\hline Guadua angustifolia Kunth & Guadua & Raro \\
\hline Phyllostachys aurea Rivière \& C. Rivière & $\begin{array}{l}\text { Bambu amarelo, bambu de } \\
\text { jardim, bambu- vara-de-pescar, } \\
\text { bambu dourado; cana-da-India }\end{array}$ & Difuso \\
\hline P. bambusoides Siebold \& Zucc. & Bambu japonês & Comum \\
\hline P. sp & - & Raro \\
\hline P. nigra (Lodd. ex Lindl.) Mundro & Bambu preto; bambu negro & Raro \\
\hline Pseudosasa japonica (Siebold \& Zucc. ex Steud.) Makino & Bambu metaque & Comum \\
\hline Sasa fortunei (Van Houtte) Fiori & Bambu-miniatura & Comum \\
\hline Sinoarundinaria falcata (Nees) C.S.Chao \& Renv. & Bambu-de-jardim & Difuso \\
\hline
\end{tabular}

erroneamente como Dendrocalamus giganteus (Figura 2).

Principais usos: No Brasil, é amplamente utilizado em estruturas de todos os portes e na fabricação de produtos em bambu laminado colado.

Uso ornamental: $O$ grande porte dos colmos e a cor marrom dos colmos jovens proporcionam beleza única à touceira deste bambu.

2- Bambusa vulgaris Schrad. ex J.C.Wendl.

Sinonímia: Bambusa auriculata Kurz, Bambusa vulgaris var. genuina Maire \& Weiller ex Maire
Nome popular: Bambu-açu, gigante verde.

Origem: Incerta, porém supõe-se que essa espécie seja nativa do chamado velho mundo, sendo os centros prováveis de origem tanto o sul da China como a Ilha de Madagascar. Foi provavelmente introduzida no Brasil pelos colonizadores portugueses.

Características: Touceiras de grande porte, até $25 \mathrm{~m}$ de altura, e diâmetro dos colmos na base pode atingir 12 $\mathrm{cm}$. Cor verde escuro. Desenvolve-se melhor a pleno sol e tolera temperaturas de até $-3^{\circ} \mathrm{C}$ (Figura 3).

Principais usos: Produção de papel e construções no meio rural. 




Figura 3. Bambusa vulgaris Schrad. ex J.C.Wendl.

Uso ornamental: A grande dimensão dos colmos, com poucos ramos basais, e sua coloração verde escura são as principais características que podem ser exploradas em um projeto paisagístico.

3- Bambusa vulgaris Schrad. ex J.C.Wendl. var. vittata Rivière

Sinonímia: Bambusa vulgaris var. aureovariegata Beadle, Bambusa vulgaris var. striata (Lodd. ex Lindl.) Gamble.

Nome popular: bambu brasil, brasileirinho, gigante verde-amarelo e bambu imperial.

Origem: Incerta, espécie pantropical. Idem Bambusa vulgaris.

Características: Touceiras de grande porte, até $25 \mathrm{~m}$ de altura, e diâmetro dos colmos na base podem atingir 12 $\mathrm{cm}$. Colmos amarelos com listras verticais verde escuras. Desenvolve-se melhor a pleno sol e tolera temperaturas de até $-3^{\circ} \mathrm{C}$ (Figura 4$)$.

Principais usos: No Brasil, é cultivada principalmente para ornamentação e usos estruturais no meio rural.

Uso ornamental: A coloração verde amarelada dos colmos é de rara beleza. A touceira geralmente é plantada isoladamente no jardim com o intuito de destacar a plasticidade dos colmos.

\section{4- Bambusa tuldoides Munro}

Sinonímia: Bambusa pallescens (Döll) Hackel, Bambusa longiflora W.T. Lin

Nome popular: taquara, bambu crioulo, bambu caipira.

Origem: China. Segundo Meredith (2001), foi trazido para o Brasil pelos colonizadores portugueses por volta de 1840 .

Características: Os colmos são de médio porte, podendo chegar a até $17 \mathrm{~m}$ de altura e $5 \mathrm{~cm}$ de diâmetro. Colmos e folhas com cores verde escuras quando maduros. Os colmos jovens apresentam coloração levemente azulada. É uma espécie totalmente adaptada ao cultivo a pleno sol e tolera temperaturas de até $-9^{\circ} \mathrm{C}$ (Figura 5).

Principais usos: É bastante utilizado para construções leves, especialmente no meio rural. É também usado para o tutoramento de culturas hortícolas.

Uso ornamental: Hábito de crescimento ereto. A coloração azulada dos colmos jovens confere uma beleza especial às touceiras desta espécie em contraste com os colmos maduros, que são mais escuros e esverdeados.

\section{5- Bambusa multiplex (Lour.) Raeusch.}

Sinonímia: Bambusa glaucescens (Willd.) Siebold ex Munro, Bambusa nana Roxb.

Nome popular: bambu-multiplex, bambu-folha-desamambaia, taquara.

Origem: China. Foi provavelmente trazido para o Brasil pelos colonizadores portugueses.

Características: touceiras de pequeno porte, até $6 \mathrm{~m}$ de altura, e diâmetro dos colmos na base podendo atingir 2,5 $\mathrm{cm}$. Apresenta folhas que lembram o padrão de folhas de samambaia e apresentam coloração azulada na face abaxial das lâminas. São encontradas na literatura em torno de 15 diferentes variedades desta espécie. Tolera sombra, porém se desenvolve melhor a pleno sol. Suporta temperaturas de até $-10^{\circ} \mathrm{C}$ (Figura 6).

Principais usos: No Brasil, o uso desta espécie se limita ao paisagismo; entretanto, na Europa e Estados Unidos, também é utilizada para a confecção de cercas e telas.

Uso ornamental: Ideal como barreira sonora e quebra- 




Figura 4. Bambusa vulgaris Schrad. ex J.C.Wendl. var. vittata Rivière

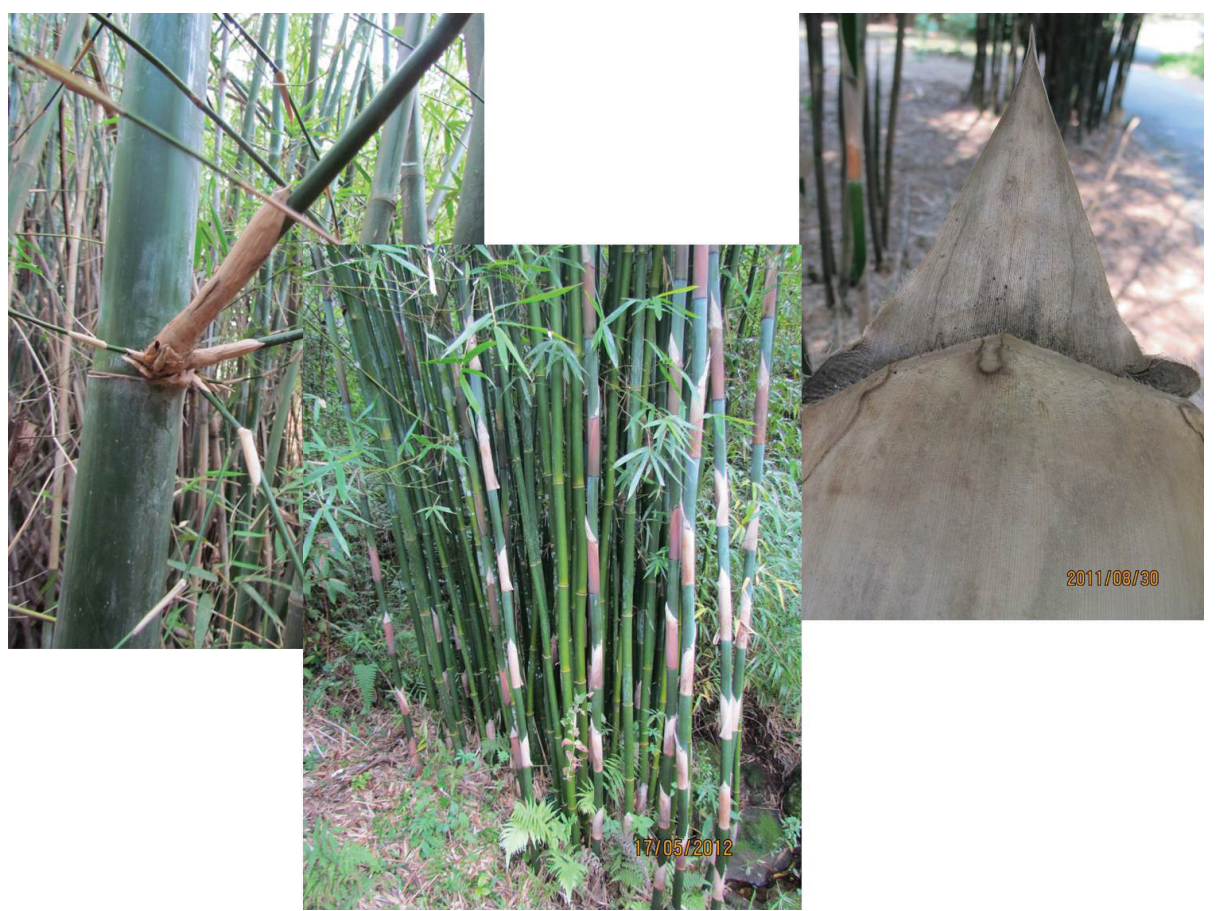

Figura 5. Bambusa tuldoides Munro.

vento. É uma espécie indicada para cultivo em vasos, graças ao seu pequeno porte. A peculiaridade da coloração e a forma de sua folhagem podem figurar como um elemento de destaque em um projeto paisagístico.

\section{6- Drepanostachyum falcatum (Nees) Keng f.}

Sinonímia: Sinoarundinaria falcata (Nees) C.S.Chao \& Renvoize $\square$ Fargesia falcata (Nees) T.P. Yi

Nome popular: bambuzinho de jardim, gracilis.

Origem: Sul da Ásia, região do Himalaia: Butão, Nepal e Índia.

Características: Bambu de pequeno porte com delicadas folhas verde claras. Apresenta colmos com 3 a $5 \mathrm{~m}$ de altura e 0,6 a $2 \mathrm{~cm}$ de diâmetro e coloração verde oliva. Pode ser cultivado a pleno sol, porém pode ocorrer o amarelamento do tom das folhas e colmos. Tolera temperaturas de até $-5^{\circ} \mathrm{C}$ (Figura 7).

Principais usos: No Brasil, é mais comumente utilizado em jardins, especialmente como cerca viva.

Uso ornamental: É uma excelente opção para cultivo em vasos e em canteiros, devido ao pequeno porte e delicado 


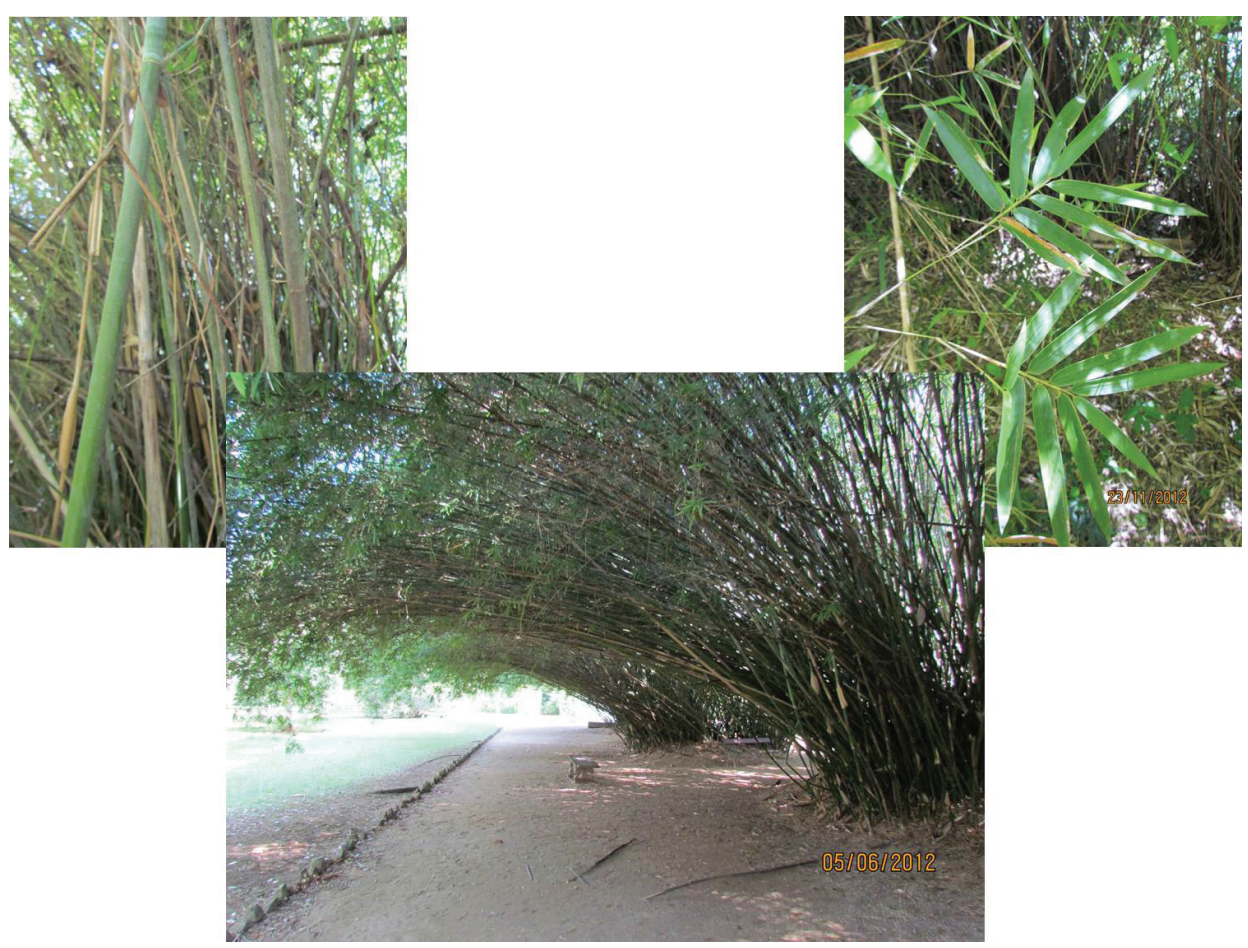

Figura 6. Bambusa multiplex (Lour.) Raeusch.



Figura 7. Drepanostachyum falcatum (Nees) Keng f.

formato da touceira. É uma espécie bastante tolerante à poda apical, por esse motivo pode ser submetida à poda do tipo topiária. Excelente para cultivo em ambientes internos.

\section{$\underline{\text { Espécies Alastrantes }}$}

\section{7- Phyllostachys edulis (Carrière) J. Houz}

Sinonímia: Phyllostachys pubescens Mazel ex J. Houz., Phyllostachys heterocycla (Carrière) S. Matsum.

Nome popular: Mossô, mossó.
Origem: China. Cultivado no Japão, foi provavelmente trazido para o Brasil pelos imigrantes japoneses na primeira metade do Século XX.

Características: Bambu de grande porte com diâmetro na base até $20 \mathrm{~cm}$, altura até $25 \mathrm{~m}$. Os colmos, quando jovens, apresentam coloração esbranquiçada. Tolera temperaturas de até $-20^{\circ} \mathrm{C}$ (Figura 8 ).

Principais usos: No Brasil, é utilizado em usos estruturais, alimentação (brotos comestíveis) e na movelaria na forma de bambu laminado colado.

Uso ornamental: É a espécie mais utilizada como 


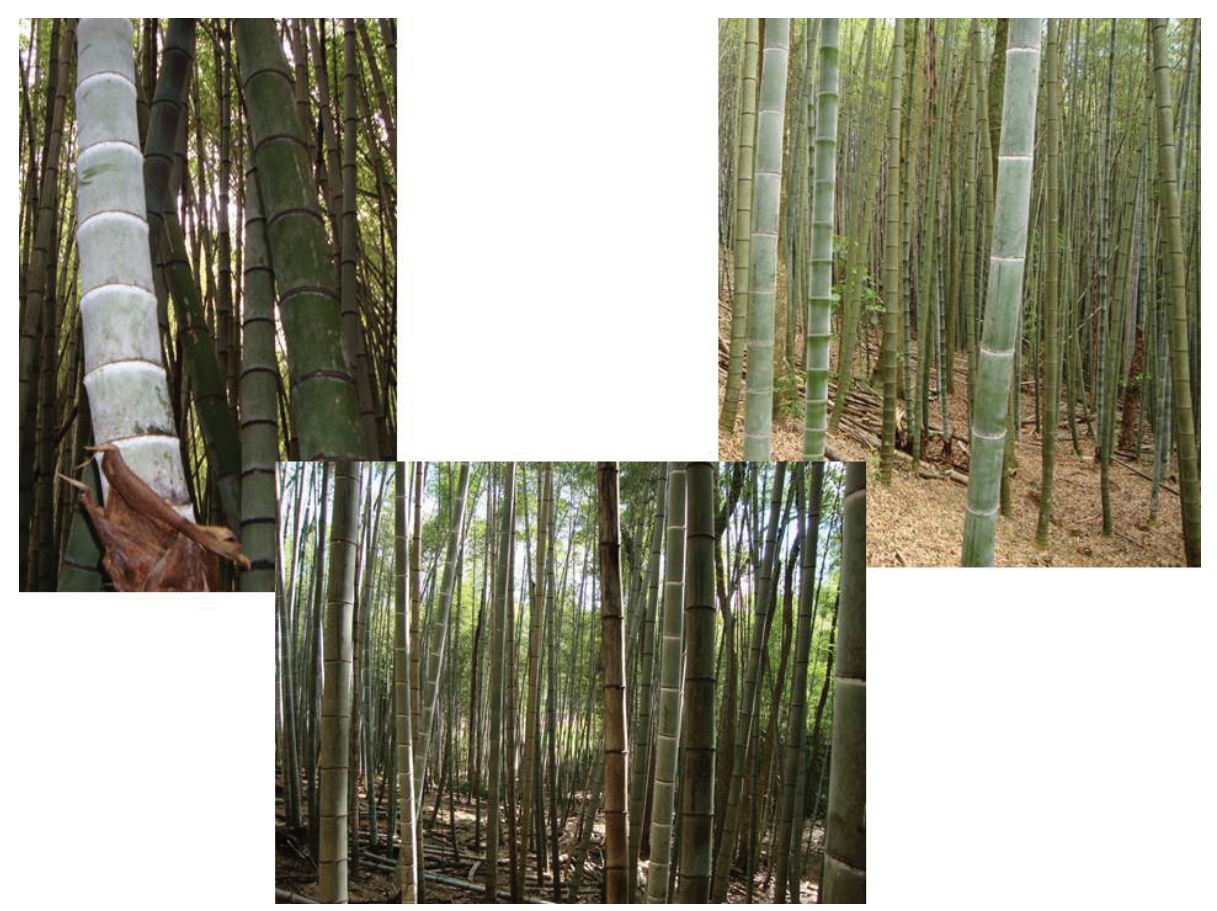

Figura 8. Phyllostachys edulis (Carrière) J. Houz.

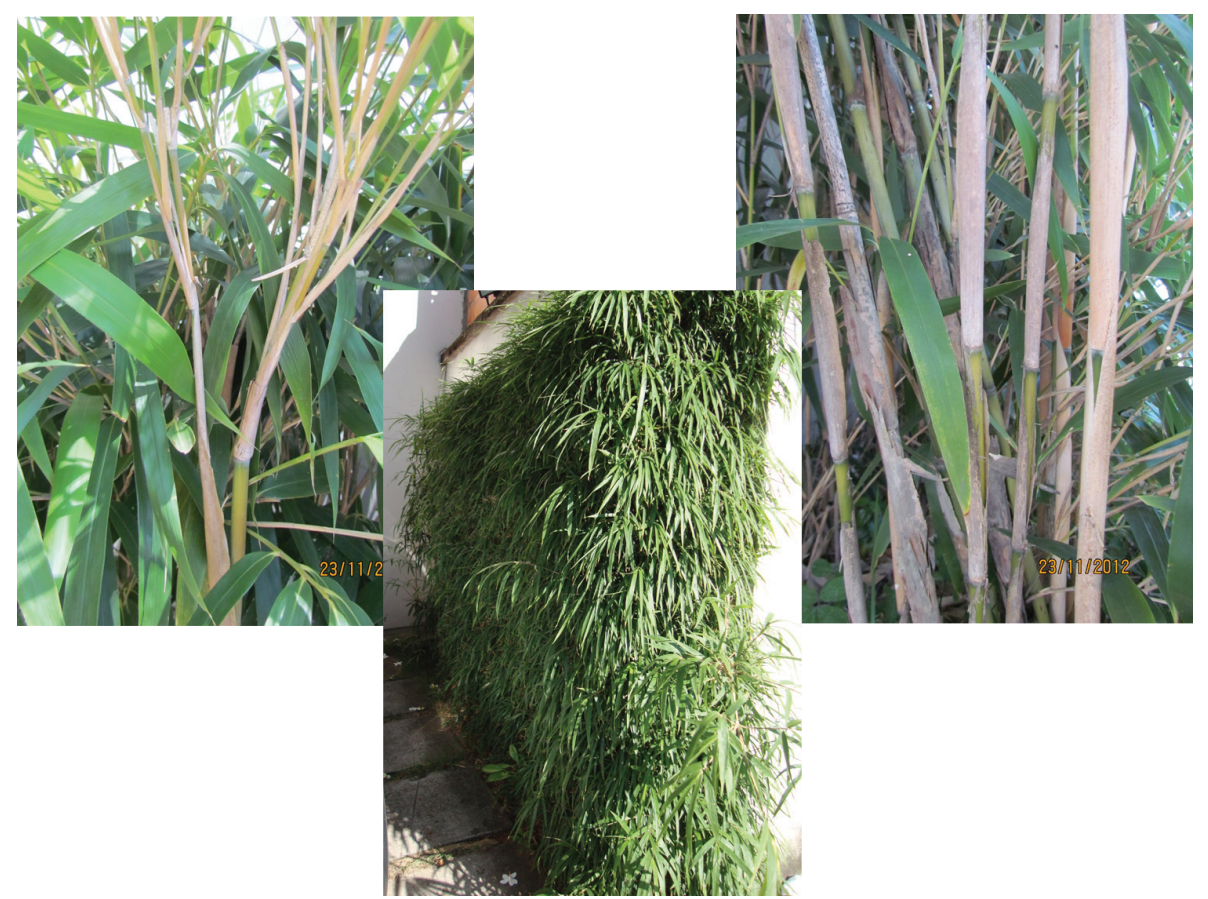

Figura 9. Pseudosasa japonica (Siebold \& Zucc. ex Steud.) Makino ex Nakai.

bambu retorcido em vasos ou jardins. A coloração mais clara dos colmos jovens contrasta com a cor mais escura dos mais velhos, conferindo um interessante efeito visual. Boa opção para a formação de bosques abertos devido à formação bastante espaçada dos brotos.

8- Pseudosasa japonica (Siebold \& Zucc. ex Steud.) Makino ex Nakai

Sinonímia: Arundinaria japonica Siebold \& Zucc. ex Steud., Sasa japonica (Siebold \& Zucc. ex Steud.) Makino

Nome popular: metake, bambuzinho de jardim
Origem: China, Japão e Coreia. Foi trazido para o país provavelmente pelos imigrantes japoneses na primeira metade do século XX.

Características: Bambu de pequeno porte com delicadas e afiladas folhas verde escuras. Os colmos podem chegar a $5 \mathrm{~m}$ de altura e $2 \mathrm{~cm}$ de diâmetro. Tolera temperaturas de até $-20^{\circ} \mathrm{C}$. É uma planta bastante rústica e tolera bem diversas condições de cultivo (Figura 9).

Principais usos: No Brasil, é mais utilizado como planta ornamental.

Uso ornamental: É excelente para cercas vivas e plantio em canteiros e áreas abertas. A disposição espacial 


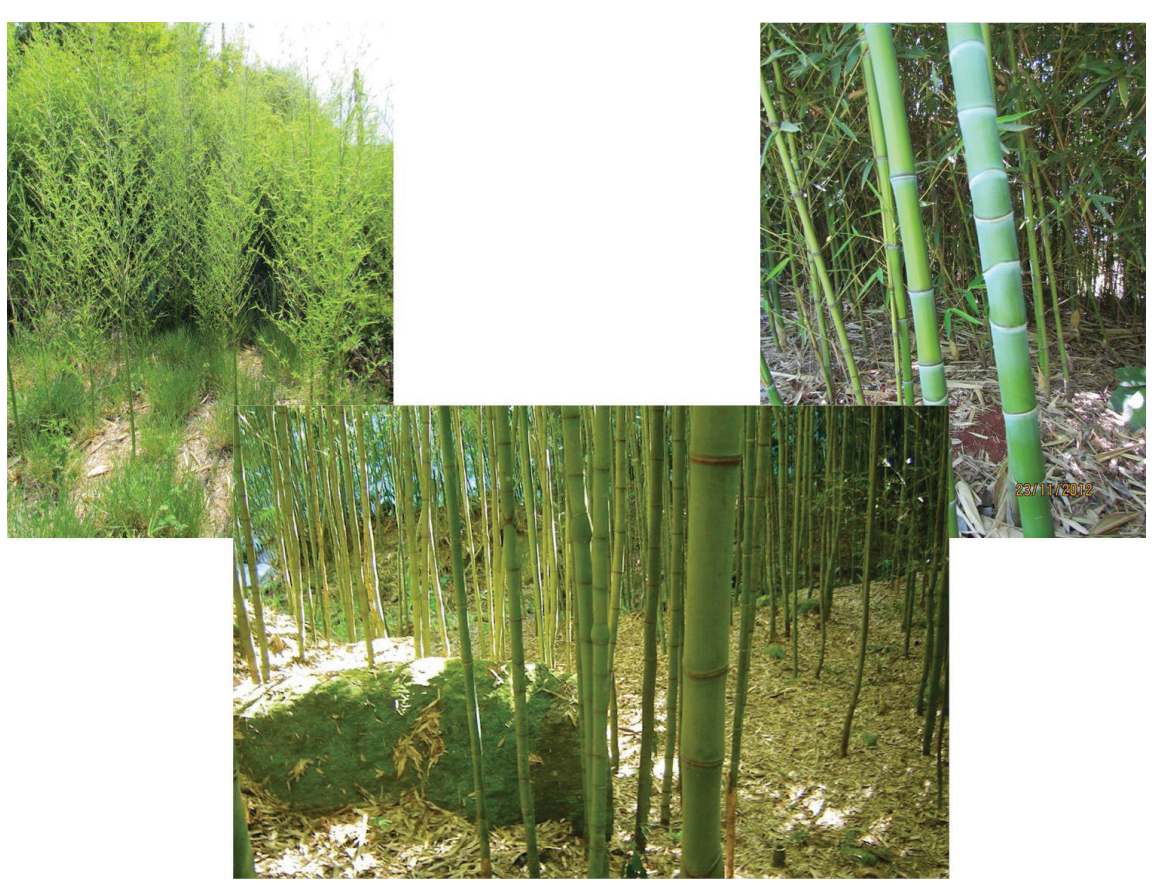

Figura 10. Phyllostachys aurea Rivière \& C. Rivière.

e a elegância dos colmos são responsáveis pela beleza peculiar de uma população desta espécie.

9- Phyllostachys aurea Rivière \& C. Rivière

Sinonímia: Phyllostachys bambusoides var. aurea (Carrière ex Rivière \& C. Rivière) Makino, Phyllostachys meyeri var. aurea (Carrière ex Rivière \& C. Rivière) Pilip.

Nome popular: cana-da-índia, bambu chinês, vara de pesca, bambu mirim, bambu dourado.

Origem: China e Japão. Foi supostamente trazido para o Brasil pelos colonizadores portugueses.

Características: Colmos de médio porte, até $8 \mathrm{~m}$ de altura, e diâmetro na base com até $3 \mathrm{~cm}$. Folhas com cores verde claras a escuras. Colmos dourados quando expostos ao sol direto e que apresentam frequentemente pequenas deformações nos entrenós, tornando-os encurtados e comprimidos, proporcionando um formato bastante peculiar e interessante visualmente. É tolerante à sombra, porém desenvolve-se melhor em pleno sol. Suporta temperaturas de até $-20^{\circ} \mathrm{C}$ (Figura 10).

Principais usos: No Brasil, é amplamente aproveitado como matéria-prima para confecção de varas de pescar, móveis e cercas. É também utilizado no meio rural para o tutoramento de culturas hortícolas.

Uso ornamental: É excelente como cerca viva e indicado para ser plantado em canteiros. Entretanto, apresenta comportamento invasivo, sendo necessária a adoção de medidas para conter e limitar seu crescimento em áreas indesejadas. Para este fim, recomenda-se a utilização de divisores de solo. Bastante resistente a fortes ventos e intempéries.

\section{0- Phyllostachys bambusoides Siebold \& Zucc.}

Sinonímia: Phyllostachys reticulata (Rupr.) K. Koch, Phyllostachys megastachya Steudel

Nome popular: madakê
Origem: China. Cultivado no Japão, foi provavelmente trazido para o Brasil pelos imigrantes japoneses na primeira metade do Século XX.

Características: Bambu de médio a grande porte, com colmos e folhas verde escuras. Atinge, no Brasil, diâmetro do colmo até $8 \mathrm{~cm}$ e altura até $20 \mathrm{~m}$. Necessita ser cultivado em áreas com boa ventilação devido à sua alta susceptibilidade a pragas. Tolera temperaturas de até $-20^{\circ} \mathrm{C}$ (Figura 11).

Principais usos: Por apresentar elevados valores de resistência mecânica, é utilizado para fins estruturais. Vem sendo mais recentemente aproveitado para a produção de móveis em bambu laminado colado.

Uso ornamental: A dimensão dos colmos e a coloração verde escura das folhas e colmos podem proporcionar um interessante contraste com o restante da vegetação de um jardim como plano de fundo. Boa opção para a formação de bosques abertos.

\section{REFERÊNCIAS}

CLAYTON, W.D. et al. (2006 onwards). GrassBase - The Online World Grass Flora. http://www.kew.org/data/ grasses-db.html. [accessed 08 nov. 2006; 15:30 GMT]

CROMPTON, D. Ornamental Bamboos. 1.ed. Portland: Timberpress, 2006. 306p

FILGUEIRAS, T.S. 2011. Bambusa in Lista de Espécies da Flora do Brasil. Jardim Botânico do Rio de Janeiro. (http://floradobrasil.jbrj.gov.br/2011/FB086783).

FILGUEIRAS, T.S. 2011. Dendrocalamus in Lista de Espécies da Flora do Brasil. Jardim Botânico do Rio de Janeiro. (http://floradobrasil.jbrj.gov.br/2011/FB105332).

FILGUEIRAS, T.S. 2011. Phyllostachys in Lista de 
Espécies da Flora do Brasil. Jardim Botânico do Rio de Janeiro. (http://floradobrasil.jbrj.gov.br/2011/ FB105402).

FILGUEIRAS, T.S. 2011. Sinarundinaria in Lista de Espécies da Flora do Brasil. Jardim Botânico do Rio de Janeiro. (http://floradobrasil.jbrj.gov.br/2011/FB105338).

FILGUEIRAS, T.S.; SANTOS-GONÇALVES, A.P. A checklist of the basal grasses and bamboos in Brazil (Poaceae). Bamboo Science \& Culture. Albany: American Bamboo Society, v.18, p.7-18, 2004.

GRECO, T. M.; CROMBERG, M. Bambu: Cultivo e Manejo. 1.ed. Florianópolis: Insular, 2011. 183p.

MEREDITH, T. J. Bamboos for Gradens. 5.ed. Portland: Timberpress, 2007. 406p.
OHRNBERGER, D. The bamboos of the world: Annotated Nomenclature and Literature of the Species and the Higher and Lower Taxa. 2.ed. Amsterdam: Elsevier Science B. V., 2002. 584p.

STAPLETON, C.M.A. Drepanostachyum falcatum var. sengteeanum: Identity and origins. Sida, 22 (2): 1081-1086 (2006).

TROPICOS.ORG. Missouri Botanical Garden. http:// www.tropicos.org/Name/25509331. Acesso em: 10 de mar. de 2012 .

VEIGA, R.F.A. et al. Levantamento de plantas ornamentais nativas mantidas sob conservação ex situ no Brasil. Revista Brasileira de Horticultura Ornamental, v.15, n.1, p.1122, 2009. 